\title{
Effects of air quality on chronic respiratory symptoms adjusted for allergy among preadolescent children
}

\author{
W. Jedrychowski, E. Flak
}

Effects of air quality on chronic respiratory symptoms adjusted for allergy among preadolescent children. W. Jedrychowski, E. Flak. OERS Journals Ltd 1998.

ABSTRACT: The aim of this study was to assess the respiratory effects of outdoor air pollution after correcting for allergy and indoor air quality.

The respiratory health survey targeted 1,129 schoolchildren, 9 yrs of age, attending schools in Krakow located in city areas differing in outdoor air pollution levels.

Chronic phlegm as a unique symptom was related neither to allergy nor to indoor variables, but was associated with the outdoor air pollution level (odds ratio (OR): 4.2; 95\% confidence interval (CI): 1.1-16.9). The same relationship has been confirmed for the self-reported local sources of industrial air pollution in the area of residence (OR: $4.2 ; 95 \%$ CI: 1.5-11.7). Hay fever appeared to be related to outdoor air pollution level (OR: 1.43; 95\% CI: 1.1-2.0) and self-reported heavy traffic (OR: 1.3; 95\% CI: 1.0-1.7). In the total sample, wheezing was connected exclusively to allergy and parental atopy, while attacks of dyspnoea with wheezing and asthma diagnosed by physician only were associated with allergy.

Since the effect of outdoor pollutants on chronic cough and wheezing (odds ratio: $1.85 ; 95 \%$ confidence interval: $1.03-3.33$ ) was only shown to be significant in the subsample of children without allergy and parental atopy, it may be postulated that either allergy is predisposing to respiratory reactions, or outdoor air pollution is coinvolved in an allergization process of the preadolescent children. Consequently, allergy should be considered as an important confound in epidemiological studies on the respiratory effects of air pollution.

Eur Respir J 1998; 11: 1312-1318.
Epidemiology and Preventive Medicine, Collegium Medicum in Jagiellonian University, Krakow, Poland.

Correspondence: W. Jedrychowski, Epidemiology and Preventive Medicine, Collegium Medicum in Jagiellonian University, 7 Kopernika Street, Krakow, Poland Fax: 48124228795

Keywords: Allergy, children, epidemiology, indoor air quality, outdoor pollution, respiratory symptoms

Received: April 31997

Accepted after revision March 91998

Supported financially by a grant from the US-Polish Maria Sklodowska-Curie Foundation (No. MZ/HHS-94-178). Principal investigator: W. Jedrychowski; Principal coinvestigators: J. Wesolowski and K-S. Liu, University of California, Berkeley, California Department of Health Services, and US Committee on Poland's Environment.
For several decades, outdoor air pollution at high concentrations has been known to cause clinically significant adverse respiratory effects in children and adults. However, several studies have also described a strong association between the prevalence of chronic respiratory symptoms and outdoor concentrations of suspended particulate matter (SPM) and sulphur dioxide $\left(\mathrm{SO}_{2}\right)$ at ambient levels [1-5].

In most epidemiological studies, air pollution data have been taken from a centrally located air-monitoring station established in a given community at the time of the health examination, or the air monitoring preceded the health survey for only a short time. Some of these studies took into account factors affecting indoor air quality, such as cigarette smoking or the use of a gas stove. However, in recent years, other indoor characteristics such as dampness or moulds in the house have also been found to be potential factors posing respiratory health risks [6-15].

During recent years more attention has also been paid to a better understanding of geographical differences in the prevalence of respiratory symptoms [16] and evidence is accumulating for a major role of allergy in the childhood onset of symptoms. This was recently supported by von Mutius et al. [17], who found that sensitization to aeroallergens accounted almost entirely for the differences in the prevalence of allergy-related respiratory symptoms between children of the former East and West Germany.
The main purpose of this study was to show which adverse respiratory effects are related to outdoor pollutant measurements (gathered under standardized procedures over longer periods preceding the health survey) and how self-reported data by parents on local air pollution sources relate to respiratory symptoms in children. The second goal of the study was to estimate the extent to which the adverse respiratory effects of outdoor air pollution could be reproduced after correction for allergy in the child and indoor air quality variables such as environmental tobacco smoke (ETS), home heating and damp or mouldy houses.

\section{Material and methods}

\section{Assessment of outdoor air pollution}

A prevalence study was conducted in Krakow, a city with approximately 700,000 inhabitants in southern Poland. Daily $24 \mathrm{~h}$ concentrations of SPM (black smoke) and $\mathrm{SO}_{2}$ were obtained over the 5-yr period preceding the health survey (1991-1995) from the city network, incorporating 17 air-monitoring stations. Monthly and seasonal means were calculated for each pollutant by averaging all available daily values. Subsequently, the spatial distribution of air pollutants over the city area was reconstructed using computer modelling from the daily values (fig. 1). 


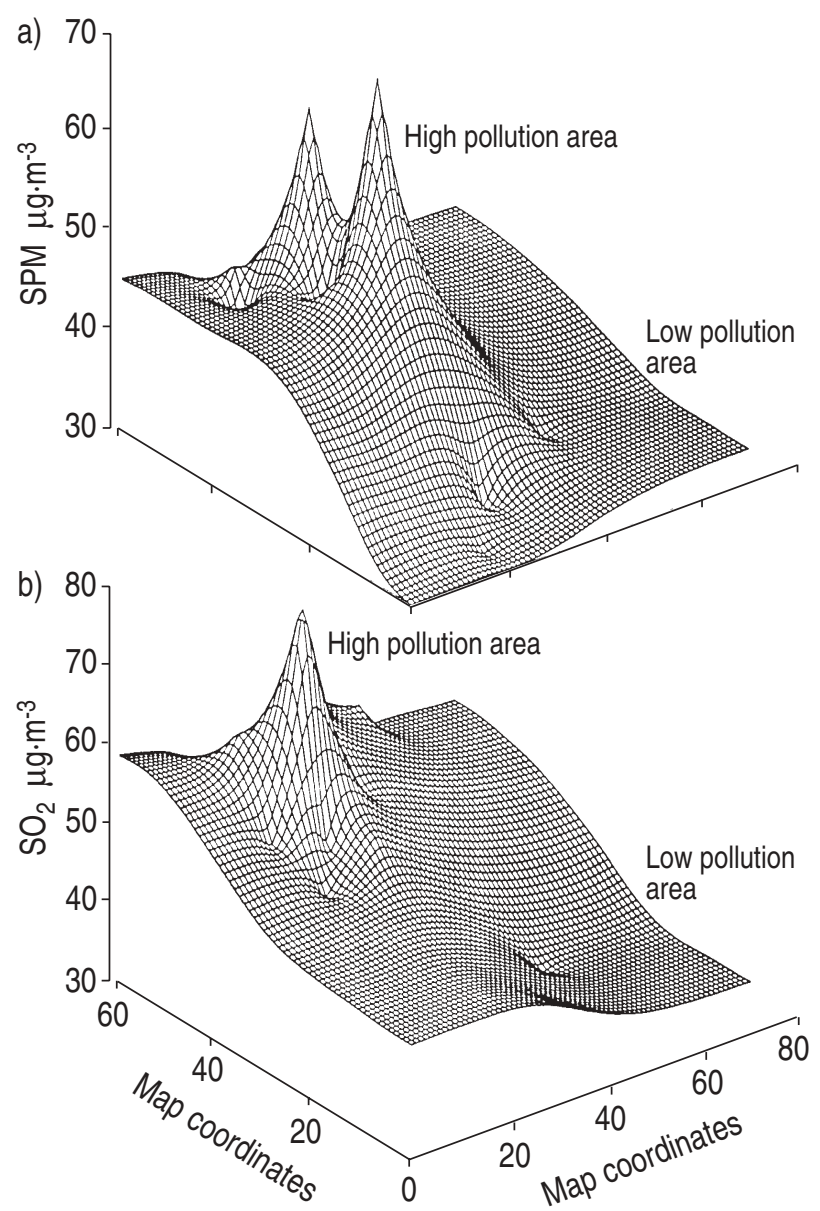

Fig. 1. - Spatial distribution of: a) suspended particulate matter (SPM); and b) sulphur dioxide $\left(\mathrm{SO}_{2}\right)$ in Krakow (1991-1995). Map coordinates: related to the city map (1:20,000 scale); 5 units correspond to $1 \mathrm{~km}$.

A three-dimensional perspective picture programme [18] was employed for computer modelling of the spatial distribution of air pollutants within the city. In the figure presented, the numbers along the abscissa and ordinate relate to coordinates on the city map $(1: 20,000)$ and 5 units correspond to a distance of $1 \mathrm{~km}$.

Anderson samplers (type MFC-HVP10; Anderson Instrument, Atlanta, USA) were used for the particle sampling in which metals were measured. The samplers aspirated air with a constant flow $\left(1.0 \mathrm{~m}^{3} \cdot \mathrm{min}^{-1}\right)$, from which dust particles of $ð 10 \mu \mathrm{m}$ in diameter were separated and depo- sited on the filter. The content of heavy metals was measured in the mineralized filters with deposited dust using the Smith-Hieftje 21/22 spectrophotometer (Thermo Jarrel Ash Corporation, Krakow, Poland).

The spatial distribution of SPM and $\mathrm{SO}_{2}$ showed that the highest levels of air pollutants were observed in the city centre and the lowest were found in the south-eastern section of the city. The high pollution area was defined as the territory within the radius of $0.5 \mathrm{~km}$ around each of tour monitoring stations with the highest measurements, while the clean area was demarcated on the street map within a radius of $0.5 \mathrm{~km}$ from each of two monitoring stations with the lowest air pollution level (APL).

In the city centre (highly polluted area), the mean level of SPM over the 5-yr period for the winter season was $103.5 \mu \mathrm{g} \cdot \mathrm{m}^{-3}$ and that of $\mathrm{SO}_{2}$ was $86.9 \mu \mathrm{g} \cdot \mathrm{m}^{-3}$. The corresponding values in the summer season were $32.3 \mu \mathrm{g} \cdot \mathrm{m}^{-3}$ and $41.8 \mu \mathrm{g} \cdot \mathrm{m}^{-3}$. Analogously, the levels of air pollutants both in the winter and summer seasons were about twofold lower in the low pollution area. In the latter area, the average concentration of SPM in the winter season was $45.4 \mu \mathrm{g} \cdot \mathrm{m}^{-3}$ and $\mathrm{SO}_{2}$ was $48.4 \mu \mathrm{g} \cdot \mathrm{m}^{-3}$. The corresponding concentrations of air pollutants in the summer season were $16.6 \mu \mathrm{g} \cdot \mathrm{m}^{-3}$ and $28.9 \mu \mathrm{g} \cdot \mathrm{m}^{-3}$. It is important to add that in the high pollution area of the city defined by classical urban pollutants (SPM and $\mathrm{SO}_{2}$ ), heavy metals also occurred in higher concentrations as well (table 1).

Additional information on the outdoor air quality considered the presence of local additional sources of air pollution. This additional information was obtained from a set of questions put to the parents on traffic density (whether house is located in a street with very heavy traffic or in the vicinity of bus stops, parking areas or street crossings) and on industrial low point emissions (whether the flat is located within $100 \mathrm{~m}$ of industrial enterprises or power plants). In the high pollution area $67.7 \%$ parents reported heavy traffic exposure and $43.7 \%$ local industry exposure, while in the low pollution area $28.8 \%$ of parents confirmed heavy traffic and $7.0 \%$ local industry exposure.

\section{Assessment of indoor air quality}

For the assessment of indoor air quality, three main variables were considered: ETS, system of home heating (gas or coal stove versus central heating) and the presence of dampness or moulds on the walls of the home.

Exposure to ETS was expressed as the presence of at least one regular cigarette smoker among parents or guardians of the child. The definition of a home with damp and

Table 1. - Mean annual atmospheric concentrations of suspended particulate matter, sulphur dioxide and heavy metals within the high and low polluted areas in 1995

\begin{tabular}{lrrrr}
\hline Variable & \multicolumn{2}{c}{ Low pollution } & \multicolumn{2}{c}{ High pollution } \\
& Mean & SD & Mean & \multicolumn{1}{c}{ SD } \\
\hline Particulate matter $\mu \mathrm{g} \cdot \mathrm{m}^{-3}$ & 33.2 & 35.99 & $52.6^{*}$ & 53.98 \\
Sulphur dioxide $\mu \mathrm{g} \cdot \mathrm{m}^{-3}$ & 31.7 & 21.93 & $43.9^{*}$ & 32.69 \\
Zinc $\mathrm{ng} \cdot \mathrm{m}^{-3}$ & 271.7 & 144.30 & $365.6^{*}$ & 208.10 \\
Copper $\mathrm{ng} \cdot \mathrm{m}^{-3}$ & 120.4 & 86.64 & 162.1 & 84.02 \\
Lead $\mathrm{ng} \cdot \mathrm{m}^{-3}$ & 139.2 & 87.76 & $343.1^{*}$ & 216.68 \\
Chromium $\mathrm{ng} \cdot \mathrm{m}^{-3}$ & 11.5 & 11.54 & 13.1 & 11.36 \\
Nickel $\mathrm{ng} \cdot \mathrm{m}^{-3}$ & 3.6 & 1.54 & $5.6^{*}$ & 3.17 \\
Cadmium $\mathrm{ng} \cdot \mathrm{m}^{-3}$ & 3.1 & 2.06 & 3.6 & 2.93
\end{tabular}

Data reproduced with permission from "The annual report in air pollution in Krakow in 1995 (Raport o stanie zanieczyszczenia powietrza w Krakowie k roku 1995)", Monograph published in Krakow, September 1996. *: $\mathrm{p}<0.05$, significant difference between areas of low and high pollution. 
mould problems was based on questions regarding moisture stains and/or visible mould growth on the walls within the household (moisture stains or mould growth $>1 \mathrm{~m}^{2}$ ).

\section{Selection of study subjects}

Regarding the spatial air pollution distribution in the Krakow area, children who lived in and attended eight schools located in the high pollution area (exposed group) and children who lived in and attended six schools from the low pollution area (reference group) were selected for study. A full list of students from these schools with their residential addresses was prepared and, consequently, parents of all 1,165 children attending the second form (9 yrs of age) of the selected schools were contacted. Out of all parents contacted, 1,129 (97\% of those eligible) agreed to be interviewed on the respiratory health of their children and household characteristics. All children lived in the area close to the school and, thus, the children living in the high pollution area attended the schools in the same area and vice versa.

\section{Survey procedures}

The cross-sectional field health survey was carried out by trained interviewers from March to June 1995. The health questionnaire contained questions on respiratory symptoms recommended by the Epidemiology Standardization Project and the American Thoracic Society (ATS) $[19,20]$. Information on household characteristics, ETS, exposure to heavy traffic or industrial low emission sources located in the residential area, and data on the allergic status of the children, as diagnosed by a doctor were also requested from the parents.

The following health respiratory outcomes in the last 12 months were collected by interview: 1) chronic cough (cough for Š3 consecutive months during the last year); 2) chronic phlegm (phlegm for $\breve{S} 3$ consecutive months during the last year); 3) wheezing or whistling in the chest, separate from or together with respiratory infections or colds; 4) wheezing with dyspnoea (attacks of wheezing with a feeling of shortness of breath); 5) breathlessness (difficulty in breathing); 6) upper respiratory symptoms (hay fever); and 7) asthma (doctor's diagnosis of asthma).

The allergic status of the child was based on the question put to the parents of whether an allergy had ever been diagnosed in the child by a physician. Parental atopy was assumed if allergic skin disorders or allergic-related respiratory diseases had ever been diagnosed by a doctor in at least one of the biological parents.

\section{Statistical analysis}

As a first step, univariate descriptive statistics were conducted on the frequency of symptoms by outdoor air pollution categories. In the second stage, multivariate logistic regression (MLR) analysis was used to calculate the prevalence odds ratio (OR) for the symptom variables adjusted for potential confounds when comparing different air pollution categories $[21,22]$. The following variables were included in the MRL models to assess their confounding effect: gender, presence of allergy in the child, parental atopy, parental education, ETS, home heating system and moulds, or dampness on the interior walls. The confounding variables were initially considered separately and then they were all included in one MRL model to assess their joint confounding effects. Descriptive and multivariate analyses were performed with BMDP statistical software (BMDP, Cork, Ireland) [23].

\section{Results}

The interviews were carried out with 1,129 parents, mainly mothers $(90.2 \%)$. No respiratory symptoms were reported for 646 children. Out of 483 children with reported symptoms, 321 had only one symptom and 162 had two or more symptoms. In table 2, the 12 -month prevalence rates (in \%) of each respiratory symptom are crosstabulated against outdoor APL and by the local sources of

Table 2. - The prevalence of chronic respiratory symptoms related to air pollution level (APL) and presence of local sources of air pollution reported by parents in the interview

\begin{tabular}{|c|c|c|c|c|c|c|}
\hline \multirow[b]{3}{*}{ Variables } & \multirow{2}{*}{\multicolumn{2}{|c|}{$\begin{array}{l}\text { Air pollution } \\
\text { level }\end{array}$}} & \multicolumn{4}{|c|}{ Local sources of air pollution } \\
\hline & & & \multicolumn{2}{|c|}{ Heavy traffic } & \multicolumn{2}{|c|}{ Local industry } \\
\hline & $\begin{array}{c}\text { Low } \\
n=600\end{array}$ & $\begin{array}{c}\text { High } \\
n=529\end{array}$ & $\begin{array}{c}\text { No } \\
n=598\end{array}$ & $\begin{array}{c}\text { Yes } \\
n=531\end{array}$ & $\begin{array}{c}\text { No } \\
n=856\end{array}$ & $\begin{array}{c}\text { Yes } \\
n=273\end{array}$ \\
\hline Chronic cough & 6.7 & 9.3 & 7.0 & 8.9 & 6.5 & $12.1^{\#}$ \\
\hline Chronic phlegm & 0.7 & $2.8^{\#}$ & 1.2 & 2.3 & 1.1 & $3.7^{\#}$ \\
\hline Breathlessness & 9.0 & 10.8 & 9.4 & 10.4 & 8.6 & $13.6 *$ \\
\hline $\begin{array}{l}\text { Wheezing without } \\
\text { respiratory infections }\end{array}$ & 4.8 & $9.1^{\#}$ & 4.8 & $9.0^{\#}$ & 6.1 & $9.2^{+}$ \\
\hline Dyspnoea attacks & 4.3 & 5.5 & 3.8 & $6.0^{+}$ & 4.6 & 5.9 \\
\hline Asthma & 1.8 & 2.3 & 1.7 & 2.5 & 2.0 & 2.2 \\
\hline Hay fever & 32.0 & $37.4^{+}$ & 30.3 & $39.4^{\#}$ & 32.9 & $39.6 *$ \\
\hline Allergy & 21.8 & 24.0 & 19.9 & $26.2 *$ & 20.3 & $30.8^{\#}$ \\
\hline Parental atopy & 28.8 & 31.4 & 24.1 & $36.5^{\#}$ & 27.0 & $39.4^{\#}$ \\
\hline Moulds/dampness & 10.3 & $25.3^{\#}$ & 13.5 & $21.7^{\#}$ & 14.7 & $25.6^{\#}$ \\
\hline ETS & 65.5 & 64.3 & 69.1 & $60.3^{\#}$ & 66.9 & $58.6 *$ \\
\hline Heating (coal/gas) & 2.0 & $42.7^{\#}$ & 13.5 & $29.6^{\#}$ & 17.8 & $31.5^{\#}$ \\
\hline $\begin{array}{l}\text { Parental education } \\
\text { (middle+high) }\end{array}$ & 72.5 & 74.8 & 70.9 & $76.6^{\#}$ & 71.7 & $79.4^{*}$ \\
\hline \multicolumn{7}{|c|}{ Crowding score $\mathrm{m}^{2}$.person-1 } \\
\hline ð 10.0 & 25.7 & $30.4^{+}$ & 29.1 & 26.6 & 27.5 & 29.3 \\
\hline$>10.0$ & 74.3 & $69.6^{+}$ & 70.9 & 73.4 & 72.5 & 70.7 \\
\hline
\end{tabular}

Data presented as percentages. ETS: environmental tobacco smoke. *: $\mathrm{p}<0.05 ;{ }^{+}$: $\mathrm{p}<0.1$; \#: $\mathrm{p}<0.005$. 
Table 3. - Prevalence odds ratios (OR) for respiratory health outcomes related to outdoor air quality, accounting for allergy in children diagnosed by a physician and household environmental factors

\begin{tabular}{|c|c|c|c|}
\hline \multirow[b]{2}{*}{ Variables } & \multirow[b]{2}{*}{$\begin{array}{c}\text { APL } \\
\text { OR }(95 \% \text { CI })\end{array}$} & \multicolumn{2}{|c|}{ LSAP } \\
\hline & & $\begin{array}{l}\text { Heavy traffic } \\
\text { OR }(95 \% \text { CI })\end{array}$ & $\begin{array}{l}\text { Local industry } \\
\text { OR }(95 \% \text { CI) }\end{array}$ \\
\hline \multicolumn{4}{|l|}{ Chronic cough } \\
\hline Outdoor air pollution & $1.56+(0.9-2.7)$ & $1.17 \ddagger(0.7-1.9)$ & $1.55^{\#}(0.9-2.6)$ \\
\hline Sex of child & $0.89(0.5-1.5)$ & $0.89(0.5-1.5)$ & $0.87(0.5-1.4)$ \\
\hline Allergy & $5.82(3.6-9.5) *$ & $5.82(3.6-9.5) *$ & $5.43(3.4-9.2)^{*}$ \\
\hline ETS & $0.70(0.4-1.2)$ & $0.70(0.4-1.2)$ & $0.71(0.4-1.2)$ \\
\hline Moulds/dampness & $0.86(0.5-1.7)$ & $0.90(0.5-1.7)$ & $0.87(0.5-1.7)$ \\
\hline Household heating & $1.21(0.6-2.3)$ & $1.48(0.8-2.6)$ & $1.43(0.8-2.5)$ \\
\hline Crowding score & $0.88(0.5-1.6)$ & $0.88(0.5-1.6)$ & $0.88(0.5-1.6)$ \\
\hline Parental atopy & $1.09(0.7-1.8)$ & $1.07(0.6-1.8)$ & $1.05(0.6-1.7)$ \\
\hline Parental education & $1.20(0.6-2.3)$ & $1.20(0.6-2.3)$ & $1.17(0.6-2.2)$ \\
\hline \multicolumn{4}{|l|}{ Chronic phlegm } \\
\hline Outdoor air pollution & $4.22+(1.1-16.9)^{*}$ & $2.18 \ddagger(0.7-6.6)$ & $4.16^{\#}(1.5-11.7)^{*}$ \\
\hline Sex of child & $0.37(0.1-1.2)$ & $0.37(0.1-1.2)$ & $0.35(0.1-1.1)$ \\
\hline Allergy & $2.00(0.7-5.5)$ & $1.92(0.7-5.3)$ & $1.76(0.6-4.9)$ \\
\hline ETS & $1.07(0.4-3.3)$ & $1.11(0.4-3.4)$ & $1.11(0.4-3.5)$ \\
\hline Moulds/dampness & $1.11(0.4-3.5)$ & $1.15(0.4-3.7)$ & $1.08(0.3-3.5)$ \\
\hline Household heating & $1.54(0.5-4.7)$ & $2.49(0.9-7.1)$ & $2.36(0.8-6.7)$ \\
\hline Crowding score & $0.70(0.2-2.1)$ & $0.68(0.2-2.0)$ & $0.70(0.2-2.1)$ \\
\hline Parental atopy & $0.99(0.3-2.8)$ & $0.96(0.3-2.8)$ & $0.89(0.3-2.6)$ \\
\hline Parental education & $0.69(0.2-2.2)$ & $0.69(0.2-2.2)$ & $0.64(0.2-2.1)$ \\
\hline \multicolumn{4}{|l|}{ Breathlessness } \\
\hline Outdoor air pollution & $1.43^{+}(0.9-2.3)$ & $1.05 \ddagger(0.7-1.6)$ & $1.41^{\#}(0.9-2.3)$ \\
\hline Sex of child & $1.05(0.7-1.6)$ & $1.05(0.7-1.6)$ & $1.04(0.7-1.6)$ \\
\hline Allergy & $4.14(2.7-6.4) *$ & $4.19(2.7-6.5) *$ & $4.07(2.6-6.3)^{*}$ \\
\hline ETS & $1.37(0.8-2.2)$ & $1.36(0.8-2.2)$ & $1.39(0.9-2.3)$ \\
\hline Moulds/dampness & $1.73(1.0-2.9)^{*}$ & $1.79(1.1-3.0)^{*}$ & $1.74(1.0-2.9) *$ \\
\hline Household heating & $0.50(0.3-0.9)^{*}$ & $0.60(0.3-1.1)$ & $0.58(0.3-1.0)$ \\
\hline Crowding score & $0.80(0.5-1.3)$ & $0.79(0.5-1.3)$ & $0.79(0.5-1.3)$ \\
\hline Parental atopy & $1.31(0.8-2.1)$ & $1.30(0.8-2.1)$ & $1.28(0.8-2.0)$ \\
\hline Parental education & $0.79(0.5-1.3)$ & $0.81(0.5-1.3)$ & $0.78(0.5-1.3)$ \\
\hline \multicolumn{4}{|l|}{ Wheezing (without respiratory infections) } \\
\hline Outdoor air pollution & $1.73+(0.9-3.2)$ & $1.52 \ddagger(0.9-2.7)$ & $1.02^{\#}(0.6-1.8)$ \\
\hline Sex of child & $1.04(0.6-1.8)$ & $1.03(0.6-1.8)$ & $1.05(0.6-1.8)$ \\
\hline Allergy & $8.54(4.9-14.8) *$ & $8.42(4.9-14.6) *$ & $8.64(5.0-15.0) *$ \\
\hline ETS & $0.76(0.4-1.3)$ & $0.75(0.4-1.3)$ & $0.75(0.4-1.3)$ \\
\hline Moulds/dampness & $1.15(0.6-2.2)$ & $1.18(0.6-2.3)$ & $1.21(0.6-2.3)$ \\
\hline Household heating & $1.76(0.9-3.4)$ & $2.12(1.2-3.8) *$ & $2.37(1.3-4.2)^{*}$ \\
\hline Crowding score & $1.42(0.7-2.8)$ & $1.40(0.7-2.7)$ & $1.40(07-2.7)$ \\
\hline Parental atopy & $1.75(1.0-3.0)^{*}$ & $1.66(1.0-2.8)^{*}$ & $1.73(1.0-2.9)^{*}$ \\
\hline Parental education & $0.70(0.4-1.3)$ & $0.68(0.4-1.3)$ & $0.70(0.4-1.3)$ \\
\hline \multicolumn{4}{|l|}{ Attacks of dyspnoea with wheezing } \\
\hline Outdoor air pollution & $0.93+(0.4-1.9)$ & 1.19 & $0.84 \#(0.4-1.7)$ \\
\hline Sex of child & $0.91(0.5-1.7)$ & $0.91(0.5-1.7)$ & $0.92(0.5-1.7)$ \\
\hline Allergy & $26.00(11.4-59.5)^{*}$ & $25.60(11.2-58.2) *$ & $26.40(11.5-60.6) *$ \\
\hline ETS & $0.87(0.5-1.7)$ & $0.88(0.5-1.7)$ & $0.87(0.5-1.7)$ \\
\hline Moulds/dampness & $0.85(0.4-1.9)$ & $0.83(0.4-1.8)$ & $0.86(0.4-1.9)$ \\
\hline Household heating & $2.02(0.9-4.6)$ & $1.83(0.9-3.7)$ & $2.00(1.0-4.0) *$ \\
\hline Crowding score & $0.98(0.5-2.1)$ & $0.98(0.5-2.1)$ & $0.99(0.5-2.1)$ \\
\hline Parental atopy & $1.35(0.7-2.5)$ & $1.32(0.7-2.5)$ & $1.36(0.7-2.5)$ \\
\hline Parental education & $0.69(0.3-1.5)$ & $0.68(0.3-1.4)$ & $0.70(0.3-1.5)$ \\
\hline \multicolumn{4}{|l|}{ Asthma diagnosed by physician } \\
\hline Outdoor air pollution & $0.70^{+}(0.2-2.1)$ & $0.90 \ddagger(0.4-2.3)$ & $0.55^{\#}(0.2-1.5)$ \\
\hline Sex of child & $1.24(0.5-3.1)$ & $1.22(0.5-3.0)$ & $1.26(0.5-3.2)$ \\
\hline Allergy & $38.00(8.6-168.0)^{*}$ & $37.40(8.4-165.0)^{*}$ & $39.60(9.0-175.0) *$ \\
\hline ETS & $0.39(0.2-1.0)$ & $0.40(0.2-1.0)$ & $0.39(0.2-1.0)$ \\
\hline Moulds/dampness & $2.52(0.9-7.1)$ & $2.38(0.9-6.5)$ & $2.51(0.9-6.9)$ \\
\hline Household heating & $1.85(0.6-6.3)$ & $1.56(0.5-4.5)$ & $1.67(0.6-4.7)$ \\
\hline Crowding score & $1.02(0.4-3.0)$ & $1.02(0.4-3.0)$ & $1.05(0.4-3.1)$ \\
\hline Parental atopy & $1.24(0.5-3.1)$ & $1.27(0.5-3.1)$ & $1.30(0.5-3.2)$ \\
\hline Parental education & $1.11(0.3-3.8)$ & $1.13(0.3-3.8)$ & $1.16(0.3-3.9)$ \\
\hline \multicolumn{4}{|l|}{ Hay fever } \\
\hline Outdoor air pollution & $1.43^{+}(1.1-2.0)^{*}$ & $1.30 *(1.0-1.7) *$ & $1.04^{\#}(0.8-1.4)$ \\
\hline Sex of child & $1.14(0.9-1.5)$ & $1.12(0.9-1.5)$ & $1.14(0.9-1.5)$ \\
\hline Allergy & $3.14(2.3-4.3) *$ & $3.12(2.3-4.3) *$ & $3.15(2.3-4.3)^{*}$ \\
\hline ETS & $0.78(0.6-1.0)$ & $0.79(0.6-1.1)$ & $0.78(0.6-1.0)$ \\
\hline Moulds/dampness & $2.16(1.5-3.1)^{*}$ & $2.20(1.5-3.2)^{*}$ & $2.24(1.6-3.2)^{*}$ \\
\hline Household heating & $0.64(0.4-0.9) *$ & $0.74(0.5-1.1)$ & $0.79(0.6-1.1)$ \\
\hline Crowding score & $1.14(0.8-1.6)$ & $1.13(0.8-1.6)$ & $1.13(0.8-1.6)$ \\
\hline Parental atopy & $1.38(1.0-1.9) *$ & $1.33(1.0-1.8) *$ & $1.37(1.0-1.8) *$ \\
\hline Parental education & $1.09(0.8-1.5)$ & $1.11(0.8-1.6)$ & $1.12(0.8-1.6)$ \\
\hline
\end{tabular}

Outdoor air pollution: +: air pollution level (APL) measured by monitoring system; $\$$ : heavy traffic reported by parents; \#: local industry exposure reported by parents. LSAP: local sources of air pollution; CI: confidence interval; ETS: environmental tobacco smoke. *: $\mathrm{p}<0.05$, significant difference between groups. 
air pollution (LSAP) reported by the parents. Crude prevalence rates of chronic cough, chronic phlegm, wheezing and hay fever were significantly higher in the more polluted area of the city. There was also a statistically significant higher prevalence of chronic cough, chronic phlegm, wheezing and hay fever in those children who lived in the streets with self-reported heavy traffic or in the vicinity of industrial emission sources.

Since the prevalence of respiratory symptoms may not only be related to residential APL, but may also depend on the indoor characteristics or the presence of allergy in children, the MLR analysis performed separately for each symptom and outdoor air pollution category (APL or LSAP) included universal confounds (child's sex, crowding index and parental education), indoor air quality variables such as home moulds or dampness, ETS, heating system (coal stoves or gas heater versus central heating), parental atopy and allergy in the child.

The comparison of adjusted-effect estimates revealed that chronic phlegm as a unique symptom was related neither to allergy nor to indoor variables, but was associated significantly with the outdoor APL (table 3). The prevalence OR for this symptom between the APL in areas of high and low outdoor air pollution was 4.2 (95\% confidence interval (CI): 1.1-16.9) and none of the potential confounding variables had a major effect on this relationship. The same pattern of relationship was observed for the self-reported local sources of industrial air pollution (OR: 4.2; 95\% CI: 1.5-11.7). Hay fever appeared to be related not only to outdoor APL (OR: $1.4 ; 95 \%$ CI: $1.1-$ 2.0 ), but also to allergy, moulds or dampness in the house, household heating and parental atopy. Self-reported heavy traffic also increased the risk of hay fever (OR: 1.3; 95\% CI: $1.0-1.7)$. The interaction term (air pollution $\times$ allergy) appeared insignificant in all MRL models.

Neither outdoor nor indoor air variables had an effect on the occurrence of chronic cough and the symptom was only associated with allergy. Breathlessness depended on allergy, the presence of moulds or dampness and the type of household heating (gas/coal versus central heating). Wheezing was related only to allergy and parental atopy, while attacks of dyspnoea with wheezing and asthma diagnosed by a physician were only associated with allergy.

The analysis performed on the same set of data when allergy and parental atopy had been removed from MRL models showed different results. Chronic cough became significantly related to APL. Moreover, the effect of outdoor APL on wheezing without respiratory infections also appeared to be significant (OR: 1.85 ; 95\% CI: 1.03-3.33). The same has been observed for heavy traffic (OR: 1.93; 95\% CI: 1.15-3.25), while the OR estimates for various air pollution indicators and the prevalence of chronic phlegm, breathlessness or hay fever were not substantially altered.

\section{Discussion}

The data showed a strong association between chronic phlegm and the level of communal air pollutants in the children's area of residence. Hay fever was also associated with APL of SPM and $\mathrm{SO}_{2}$, and this association remained significant after adjustment for allergy, parental atopy and household characteristics. Of the LSAP reported by parents, the presence of industrial sources of emission aff- ected the occurrence of chronic phlegm and the presence of heavy traffic was associated with hay fever. As most of the children (80\%) from the area with the high level of pollutants were exposed to heavy traffic or the presence of local industrial pollution, it was impossible to assess separately the contribution of the different sources of air pollutants to the occurrence of respiratory symptoms.

The study results provided further evidence that, besides outdoor APL, allergy is implicated in the occurrence of respiratory symptoms [24-29]. However, in the present study it was found that after adjustment for allergy and indoor air quality, neither wheezing nor asthma was more prevalent in the areas of the city with the higher level of communal air pollutants. The analysis performed on the same set of data when allergy and parental atopy had been removed from MRL models showed that, besides chronic cough, wheezing also appeared to be significantly related to the outdoor APL. The same has been observed for heavy traffic, but the OR estimates for various air pollution indicators and chronic phlegm, breathlessness or hay fever were not substantially altered.

These results are in good agreement with the study of DOCKERY et al. [1], in which an increase in respiratory symptoms (cough and bronchitis) across the six cities in USA was found to be associated with SPM in these communities. In their study a particularly strong association with the symptoms was found for particles with a $50 \%$ cut-off aerodynamic diameter of $15 \mu \mathrm{m}$, but no associations were disclosed for asthma, persistent wheeze or hay fever.

In the present study, the increase of respiratory symptoms such as chronic phlegm and hay fever was particularly clear in the area with the high level of communal classic air pollutants (SPM and $\mathrm{SO}_{2}$ ). However, in this epidemiological study it was impossible to demonstrate the effect of a specific pollutant as both pollutants were present at about the same concentration within the highly polluted area, and higher levels of lead and other heavy metals also occurred. These latter pollutants originate mainly from traffic. Therefore, the importance of other pollutants, such as motor vehicle emissions, in the occurrence of respiratory symptoms cannot be excluded [30 32].

In the analysis of various respiratory health outcomes possibly related to air pollution, the potential confounding effect of several variables was evaluated. The education level of the parents and the crowding index were used as indicators of the socioeconomic status of the family, but these variables showed no major confounding effect. Of the other confounding factors, such as indoor characteristics (moulds or dampness, ETS and type of home heating system), that could be implicated in the observed association between symptoms and air pollution, only the presence of moulds or dampness or household heating were significant in some MRL models. Studies carried out in many countries have reported that living in a damp or mouldy home is associated with respiratory infections and other adverse effects, among both children and adults, and their effect may be even stronger than that of outdoor pollution [33-39]. In the present study, moulds or dampness was only shown to affect hay fever and breathlessness. In fact, the effect of this characteristic on hay fever was stronger than that of outdoor pollution.

The effects of ETS and type of household heating (coal or gas versus central heating) appeared to be of minor 
importance for chronic cough, chronic phlegm or wheezing; however, these factors were relevant for breathlessness and hay fever. The lack of effect of ETS may result from the stronger impact of other indoor variables, such as moulds or dampness, or from the fact that parents are more likely to quit cigarette smoking if their children are suffering from chronic respiratory symptoms.

Measures of health outcome and data on the exposure to indoor air quality and supplemental sources of outdoor pollution were based on reports by parents, which may be subject to misclassification. First, information on traffic or industrial emissions outside the home may not reflect the actual exposure. However, the risk estimates for chronic phlegm and hay fever for air pollution categories based on measurements were similar to those based on self-reported exposure data. Secondly, parents experiencing atopyrelated respiratory diseases may have different perceptions of the possible unhealthy effects of air pollutant emissions, which could result in preferential reporting of exposure among their children, especially in those who have respiratory symptoms. Although bias due to parental atopy cannot be disproved easily, the observed association between air pollutants and respiratory symptoms adjusted for parental atopy to some extent protects against this type of bias.

Another weakness of this study may result from the cross-sectional approach used in collecting the data, however, many of the exposure variables refer not only to present but also to past experience (air pollution measurements over a 5-yr period) and the frequency of respiratory symptoms refers to the 12-month period preceding the survey. Finally, another point limiting the strength of this paper is the definition of allergy, which was based on parents' reports. It was not made clear whether subjects were sensitive to indoor or outdoor allergens. This limits the possibility of interpreting the data in aetiological terms. Misclassification errors, mainly underestimation of the prevalence of allergy across the exposure areas, could distort the estimated risk, but only if they were differential in nature. However, adjustment of risk estimates to the wide range of socioeconomic and environmental characteristics of the children largely limits the effect of this source of bias.

In conclusion, this study indicates that the prevalence of chronic respiratory symptoms among preadolescent children is related to a rather small extent to outdoor pollutants when the effect of allergy is considered simultaneously in the analysis. Since the effect of outdoor pollutants, particularly on wheezing and chronic cough, was shown to be significant only in the subsample of children without allergy and parental atopy, it may be postulated that either allergy is predisposing to respiratory reactions or outdoor air pollution is coinvolved in an allergization process. Consequently, allergy should be considered as an important confound in measuring the effect of air pollutants. Amongst the indoor sources of air pollution, only the presence of gas heating, coal stoves and moulds or dampness in the households pose an increased risk for respiratory symptoms.

\section{References}

1. Dockery DW, Speizer FE, Stram DO, Ware JH, Spengler JD, Ferris BG Jr. Effects of inhalable particles on respiratory health of children. Am Rev Respir Dis 1989; 139: 587-594.
2. Dodge R, Solomon P, Moyers J, Hayers C. A longitudinal study of children exposed to sulphur oxides. Am J Epidemiol 1985; 121: 720-736.

3. Ware JH, Ferris BG Jr, Dockery DW, Spengler JD, Stram DO, Speizer FE. Effects of sulphur oxides and suspended particles on respiratory health of preadolescent children. Am Rev Respir Dis 1986; 133: 834-842.

4. Krzyzanowski M, Jedrychowski W, Wysocki M. Factors associated with the change in ventilatory function and the development of chronic obstructive disease in a 13-year follow-up of the Cracow study. Am Rev Respir Dis 1986; 134: 1011-1019.

5. Jedrychowski W, Krzyzanowski M. Ventilatory lung function and chronic chest symptoms among the inhabitants of urban areas with various levels of acid aerosols: prospective study in Cracow. Environ Health Perspect 1989; 79: 101-107.

6. Brunekreef B, Dockery DW, Speizer FE, Ware JH, Spengler JD, Ferris BG. Home dampness and respiratory morbidity in children. Am Rev Respir Dis 1989; 140: 1363-1367.

7. Colley JRT, Holland WW, Corkhill RT. Influence of passive smoking and parental phlegm on pneumonia and bronchitis in early childhood. Lancet 1974; ii: 1031-1034.

8. Dales RE, Burnett R, Zwaneburg H. Adverse health effects among adults exposed to home dampness and molds. Am Rev Respir Dis 1991; 143: 505-509.

9. Dijkstra L, Houthuijs D, Brunekreef B. Respiratory health effects of the indoor environment in a population of Dutch children. Am Rev Respir Dis 1990; 142: 1172-1178.

10. Jedrychowski W, Flak E. Maternal smoking in pregnancy and postnatal environmental tobacco smoke exposure as predisposing factors in older children to acute respiratory infections. Environ Health Perspect 1997; 105: 302-306.

11. Martin CJ, Platt SD, Hunt SM. Housing conditions and ill health. Br Med J 1987; 294: 1125-1127.

12. Neas LM, Dockery DW, Ware JH, Spengler JD, Ferris BG Jr, Speizer FE. Concentration of indoor particulate matter as a determinant of respiratory health in children. Am J Epidemiol 1994; 139: 1088-1099.

13. Ware JH, Dockery DW, Spiro A, Speizer FE, Ferris BG Jr. Passive smoking, gas cooking, and respiratory health of children living in six cities. Am Rev Respir Dis 1984; 129: $366-374$.

14. Weiss ST, Tager IB, Speizer FE. Persistent wheeze: its relation to respiratory illness, cigarette smoking, and levels of pulmonary function in a population sample of children. Am Rev Respir Dis 1980; 122: 697-707.

15. Platt SD, Martin CJ, Hunt SM, Lewis ChW. Damp housing, mould growth, and symptomatic health state. $B M J$ 1989; 298: 1673-1678.

16. Braback L, Breborowicz A, Dreborg S, Knutson A, Pieklik H, Bjorksten B. Atopic sensitization and respiratory symptoms among Polish and Swedish school children. Clin Exp Allergy 1994; 24: 826-835.

17. Mutius E von, Martinez FD, Fritzsch C, Nicolai T, Roll $\mathrm{G}$, Thieman H-H. Prevalence of asthma and atopy in two areas of West and East Germany. Am J Respir Crit Care Med 1994; 149: 358-364.

18. Porter Cobey, 3-dimensional perspective picture. Atlantic Oceanographic Laboratory, Computer Note, 1971; 4C. (Program RW3D from CFNPLOT Library).

19. Ferris BG Jr. Epidemiologic standardization project. II Childhood respiratory symptoms questionnaire. Am Rev Respir Dis 1978; 118: Suppl. 6, 7-53.

20. American Thoracic Society. Epidemiology Standardization Project, executive committee. Recommended res- 
piratory disease questionnaire for use with adults and children in epidemiological research. Am Rev Respir Dis 1978; 118: 7-52.

21. Hosmer D, Lemeshow S. Applied Logistic Regression. New York, Wiley, 1989.

22. Kelsey JL, Whittemore AS, Evans AS, Thomson WD. Methods in Observational Epidemiology. 2nd Edn. New York, Oxford University Press, 1996; pp. 229-236.

23. BMDP Manual, 1990 version, Los Angeles, 1991.

24. Kaneko S, Shimada K, Horiuchi H. Nasal allergy and air pollution. Oto-Rhino-Laryngology (Tokyo) 1980; 23: Suppl. 4, 270.

25. Nowak D, Heinrich J, Jorres R, et al. Prevalence of respiratory symptoms, bronchial hyperresponsiveness and atopy among adults: West and East Germany. Eur Respir $J$ 1996; 9: 2541-2552.

26. Ninan TK, Russel G. Respiratory symptoms and atopy in Aberdeen schoolchildren: evidence from two surveys 25 years apart. BMJ 1992; 304: 873-875.

27. Trepka MJ, Heinrich J, Wichman HE. The epidemiology of atopic diseases in Germany: an East-West comparison. Rev Environ Health 1996; 11: 119-131.

28. Stiller-Winkler R, Idel H, Leng G, Spix C, Dolgner R. Influence of air pollution on humoral immune response. $J$ Clin Epidemiol 1996; 49: 527-534.

29. Ishizaki T, Koizumi K, Ikemori R, Ishiyama Y, Kushibiki E. Studies of prevalence of Japanese cedar pollinosis among the residents in a densely cultivated area. Ann Allergy 1987; 58: 265-270.

30. Wjst M, Reitmeir P, Dold S, et al. Road traffic and ad- verse effects on respiratory health in children. $B M J 1993$; 307: 596-600.

31. Miguel AG, Cass GR, Weiss J, Glovsky M. Latex allergens in tire dust and airborne particles. Environ Health Perspect 1996; 104: 1180-1186.

32. Duhme H, Weiland SK, Keil U, et al. The association between self-reported symptoms of asthma and allergic rhinitis and self-reported traffic density on street of residence in adolescents. Epidemiology 1996; 7: 578-582.

33. Korsgaard I, Korsgaard J. Mite asthma and residency. Am Rev Respir Dis 1983; 128: 231-235.

34. Pirrhonen I, Nevalainen A, Husman T, Pekkanen J. Home dampness, moulds and their influence on respiratory infections and symptoms in adults in Finland. Eur Respir $J$ 1996; 9: 2618-2622.

35. Smith JM. Clinical findings in children with allergy to the house dust mites. Acta Allerg 1970; 25: 37-40.

36. Strachan DP. Damp housing and childhood asthma: validation of reporting of symptoms. Br Med J 1988; 297: 1223-1226.

37. Verhoeff AP, van Strien RT, van Wijnen JH, Brunekreef B. Damp housing and childhood respiratory symptoms: the role of sensitization to dust mites and molds. Am J Epidemiol 1995; 141: 103-110.

38. Voorhorst R, Spieksma-Boezeman MIA, Spieksma FThM. Is a mite (Dermatophagoides) the producer of the housedust allergen? Allerg Asthma 1964; 10: 329-334.

39. Wagemaekers M, Wageningen van N, Brunekreef B, Boleij SM. Respiratory symptoms in damp houses. A pilot study. Allergy 1989; 44: 192-198. 